\section{Evaluasi Tinglkat \\ Keseragaman Beton dan Sifat Mekanis Beton di Lapangan dengan Penerapan Schmidt Hammer Test dan Metode Core Drilled Test}

\section{Nursiah Chairunnisa}

Mahasiswa Program Profesi Insinyur, Universitas Lambung Mangkurat

nursiah.chairunnisa@ulm.ac.id
Penilaian dari beton dalam suatu konstruksi memegang peranan penting untuk mengetahui kekuatan, durabilitas dan kondisi suatu struktur yang sedang dan atau telah di bangun. Evaluasi pengujian sifat beton dapat dilakukan dengan beberapa metode yaitu metode destruktif dan non destruktif. Dalam artikel ini, pengujian tidak merusak dengan menggunakan Schmidt hammer test bertujuan untuk indikasi awal penentuan keseragaman beton dan sebagai tolak ukur untuk melakukan pengujian merusak dengan core drilled test yang dilakukan untuk mengevaluasi sifat mekanis beton di Lapangan. Hasil evaluasi pada studi kasus dengan pengujian tidak merusak menunjukkan koefisien variasi beton melebihi angka $6 \%$ maka beton diindikasi memiliki tingkat keseragaman yang kurang baik sehingga diperlukan assessment pengujian merusak. Hasil evaluasi pengujian merusak dengan alat core-drilled menunjukkan bahwa kuat tekan beton inti yang diperoleh dari sampel beton inti (core drilled samples) untuk elemen struktur pile cap adalah rata-rata sebesar 21 MPa. Hasil pengujian merusak dengan core drill test untuk sampel beton inti tidak memenuhi persyaratan penerimaan sampel berdasarkan SNI 6680:2016 untuk target mutu $25 \mathrm{MPa}$.

Kata kunci: beton, kuat tekan beton, koefisien variasi pengujian merusak (destructive test) pengujian tidak merusak (non-destructive test)

Diajukan: 3 Juni 2020

Direvisi: 17 Juni 2020

Diterima: 24 September 2020

Dipublikasikan online: 27 September 2020

\section{Pendahuluan}

Beton adalah material konstruksi yang sangat substansial dan umum yang digunakan didunia konstruksi karena tingkat durabilitas dan kemampuan layan tinggi. Terkadang, diperlukan untuk menguji struktur beton setelah beton mengeras untuk menentukan apakah struktur tersebut sesuai dengan perencanaan atau tidak. Idealnya, pengujian yang dilakukan adalah tanpa merusak beton eksisting (nondestructive test) dan pengujian merusak (destructive test).

Pengujian non-destructive test ini adalah pengujian dimana tidak ada kerusakan pada beton saat pengujian. Tujuan utama dari pengujian tidak merusak adalah untuk menilai kekuatan elemen beton di Lapangan dalam hal densitas, durability dan kadar air. Pengujian tidak merusak juga dapat mengetahui kedalaman retak dan menginvestigasi adanya kerusakan elemen struktur yang terjadi. Beberapa metode pengujian tidak merusak adalah pengujian dengan menggunakan metode penggunaan palu beton (hammer test), Ultrasonic Pulse velocity (UPV) method. Menurut Hannachi dan Nacer, 2012 bahwa pemantauan health monitoring system dari struktur dapat dilakukan dengan menggunakan pendekatan pengujian tidak merusak berupa uji palu beton (hammer test) dan metode kecepatan pulsa (Ultrasonic Pulse velocity, UPV).

Pengujian merusak (destructive test) adalah pengujian merusak sebagian dari elemen struktur seperti core drill test dimana permukaan struktur yang mengalami kerusakan harus segera diperbaiki setelah pengujian dilakukan. Evaluasi kelayakan struktur dengan menggunakan alat Schmidt hammer test dan core drilled test telah dilakukan oleh peneliti sebelumnya (Mawardi L, 2003; Christiawan I dkk, 2008 dan Karundeng V.S, 2015). Lebih lanjut penelitian tentang pengujian merusak dan tidak merusak telah dilakukan oleh peneliti sebelumnya (Aydin, $F$ dan Saribiyik, M, 2010; Patil, S.G. \& Suresh, 2017; Alexandre, B.J., dkk, 2013; Malek, J. \& Kaouther, M, 2014; Breysse, D, 2012).

Dalam artikel ini akan menjelaskan tentang evaluasi sifat mekanis beton dalam hal ini mutu beton dengan menggunakan pengujian tidak merusak untuk menentukan tingkat keseragaman beton dan pengujian merusak untuk menentukan mutu beton pada elemen struktur pile cap salah satu bangunan layanan publik di Kalimantan Selatan. Tujuan Akhir dari pengujian ini adalah untuk mengetahui berapa mutu beton eksisting yang terjadi pada elemen struktur tersebut.

Cara mensitasi artikel ini:

Chairunnisa, N (2020) Evaluasi Tingkat Keseragaman Beton dan Sifat Mekanis Beton di Lapangan dengan Penerapan Schmidt Hammer Test dan Metode Core Drilled Test. Buletin Profesi Insinyur 3(2) 089-094 


\section{Metode}

\section{Schmidt Rebound Hammer Test}

\section{Pengujian Tidak Merusak (Non-destructive test)}

Hammer rebound Schmidt pada dasarnya adalah pengujian kekerasan permukaan yang bekerja berdasarkan prinsip bahwa rebound massa elastis yang tergantung pada kekerasan permukaan. Ada hubungan teoretis antara kekuatan beton dan angka rebound dari hammer test dalam batas korelasi empiris yang telah ditetapkan antara sifat sifat kekuatan dan juga nomor pantulan. Alat Schmidt Hammer test ditunjukkan pada Gambar 1. Umumnya Palu memiliki berat sekitar 1,8 kg dan cocok untuk digunakan baik di laboratorium maupun di lapangan. Schmidt Hammer Test bisa digunakan secara horizontal, vertikal atau posisi vertikal ke bawah serta di setiap sudut menengah dengan cara palu hammer tegak lurus dengan permukaan yang diuji. Kode aturan untuk penggunaan alat pantul ini berdasarkan SNI 6680-2016 yang berdasarkan ASTM C 805. SNI 6880-2016 menguraikan pasal tentang pengujian nondestruktif untuk keseragaman beton pada elemen struktur yaitu menggunakan palu beton (hammer test) sesuai dengan ASTM C805 dan atau metode kecepatan pulsa (ultrasonic pulse velocity UPV test) dengan ASTM C597. Lebih lanjut penggunaan pengujian ini ditujukan sebagai dasar dalam pemilihan lokasi pengambilan sampel pada uji merusak dengan pengambilan beton inti (core drill test).

Grafik korelasi angka Rebound Hammer Test dan keseragaman kuat tekan beton ditunjukkan pada Gambar 2 .

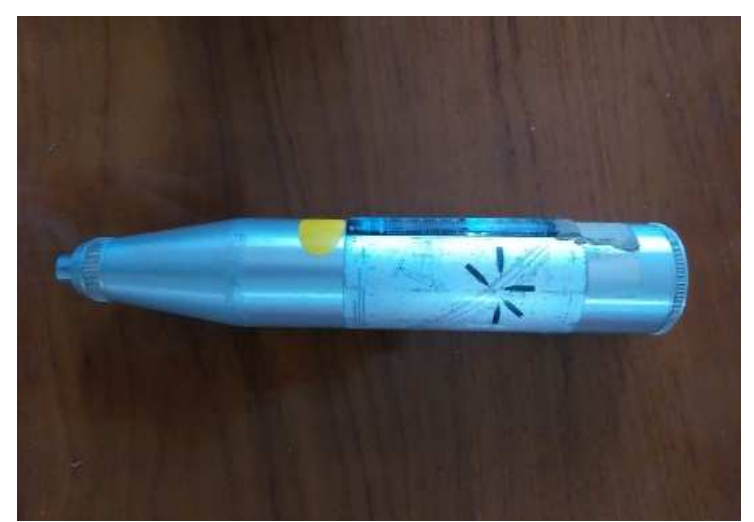

Gambar 1. Schmidt hammer test

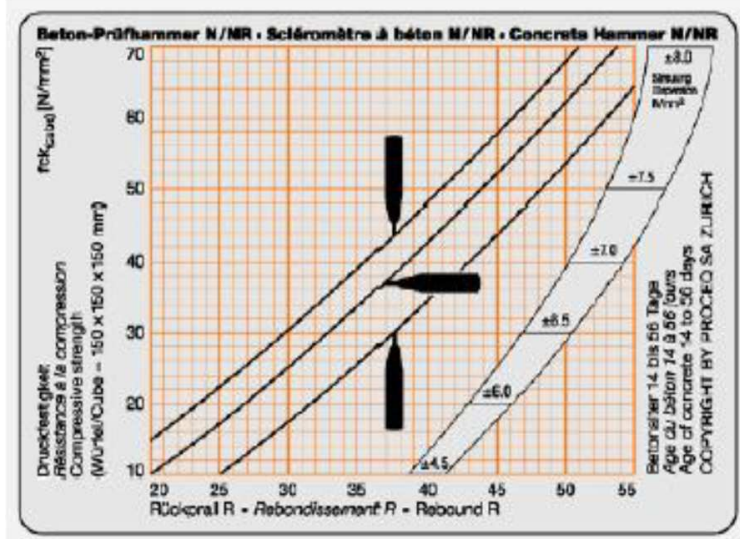

Gambar 2. Grafik korelasi nilai rebound hammer (R) dan keseragaman beton

\section{Pengujian Merusak (Coredrill test)}

Pengujian merusak (Destructive test) yang digunakan dalam proyek ini adalah coredrilled test yaitu pengujian merusak dengan mengambil sampel inti dari beton untuk memberikan informasi tentang sifat mekanik beton dari struktur yang ada. Sampel core drilled juga dapat dipergunakan sebagai alat kontrol kualitas ketika ada masalah dengan kualitas material beton atau proses pelaksanaan pengecoran yang dilakukan. Informasi sifat mekanis beton dapat diperoleh dengan penilaian inti lebih lanjut. Kode aturan yang digunakan untuk pengambilan beton inti berdasarkan SNI 02-2492-2002.

Menurut SNI 6880-2016 menguraikan bahwa benda uji beton inti merupakan sampel beton yang berbentuk silinder hasil pengeboran beton pada elemen struktur di Lapangan. Beton inti harus diuji tidak kurang dari 48 jam setelah pengeboran atau pembasahan terakhir dan selambatlambatnya 7 hari setelah inti beton dibor dari struktur, kecuali disyaratkan lain dan dari setiap lokasi beton pada elemen struktur yang akan dilakukan pengujian beton inti harus diambil minimal tiga beton inti yang mewakili.

Kuat tekan beton hasil coredrilled test merupakan kuat tekan yang sudah dikoreksi yang dipengaruhi faktor $C_{0}, C_{1}$ dan $C_{2}$.

\section{Faktor Pengali $\mathrm{C}_{0}$}

Faktor pengali $\mathrm{C}_{\mathrm{o}}$ adalah arah pengambilan benda uji beton inti pada elemen struktur yang ditentukan pada Tabel 1.

Tabel 1. Faktor Pengali $C_{0}$ pada benda uji beton inti

\begin{tabular}{lc}
\hline $\begin{array}{c}\text { Arah pengambilan sampel } \\
\text { dari beton inti }\end{array}$ & $\mathrm{C}_{0}$ \\
\hline Horizontal & 1 \\
\hline vertikal & 0,92 \\
\hline
\end{tabular}

\section{Faktor Pengali $C_{1}$}

Faktor pengali $C_{1}$ berhubungan dengan rasio panjang setelah diberi lapisan caping dengan diameter benda uji beton inti. Menurut SNI, jika rasio Panjang dan diameter melebihi 1,94 nilai $C_{1}$ adalah berdasarkan Tabel 2.

Tabel 2. Faktor Pengali $C 1$ pada benda uji beton inti

\begin{tabular}{cc}
\hline L/D & $C_{1}$ \\
\hline 1,00 & 0,93 \\
\hline 1,50 & 0,96 \\
\hline 1,75 & 0,98 \\
\hline 2,00 & 1,00 \\
\hline
\end{tabular}

\section{Faktor Pengali $C_{2}$}

Faktor $\mathrm{C}_{2}$ adalah factor pengali keberadaan tulangan baja dalam beton inti jika terdapat 1 tulangan dihitung berdasarkan Persamaan 1 dan jika terdapat lebih dari satu tulangan dalam beton inti maka dapat dirumuskan berdasarkan Persamaan 2.

$$
\begin{aligned}
& C_{2}=1+1,5\left(\frac{d}{D} x \frac{h}{l}\right) \\
& C_{2}=1+1,5 \frac{\sum(d x h)}{D x l}
\end{aligned}
$$

Dengan $d$ adalah diameter tulangan $(\mathrm{mm})$, D adalah diameter benda uji $(\mathrm{mm}), \mathrm{h}$ adalah jarak terpendek antara sumbu tulangan dengan ujung benda uji $(\mathrm{mm})$, I adalah 
Panjang benda uji sebelum diberi lapisan caping $(\mathrm{mm})$ dan $\mathrm{fc}^{\prime}$ adalah kuat tekan beton inti terkoreksi yang di dihitung berdasarkan Persamaan 3.

$$
f_{c(\text { terkoreksi })}^{\prime}=f_{c}^{\prime} C_{0} C_{1} C_{2}
$$

SNI 6680:2016 tentang persyaratan beton struktural untuk bangunan Gedung mensyaratkan bahwa batas minimum kuat tekan rata-rata benda uji adalah $85 \%$ dari $f_{c}{ }^{\prime}$ dan tidak ada sampel yang bernilai dibawah $75 \% \mathrm{f}_{\mathrm{c}}{ }^{\prime}$

Secara umum kuat tekan beton inti diperoleh dengan menggunakan alat uji kuat tekan beton (Compressive testing machine) yang ditunjukkan pada Gambar 3 dan dihitung berdarakan Persamaan (4).

$$
\boldsymbol{f}_{c}^{\prime}=\frac{P}{\boldsymbol{A}}
$$

Dengan $f_{c}^{\prime}$ adalah mutu beton (MPa), $\mathrm{P}$ adalah beban uji hancur berdasarkan alat uji kuat tekan (N) dan A adalah luas penampang benda uji beton inti $(\mathrm{mm})$. Menurut SNI 032492-2002 tentang Metode Pengambilan dan Pengujian Beton Inti, ketelitiannya bisa mencapai $0.5 \mathrm{MPa}$

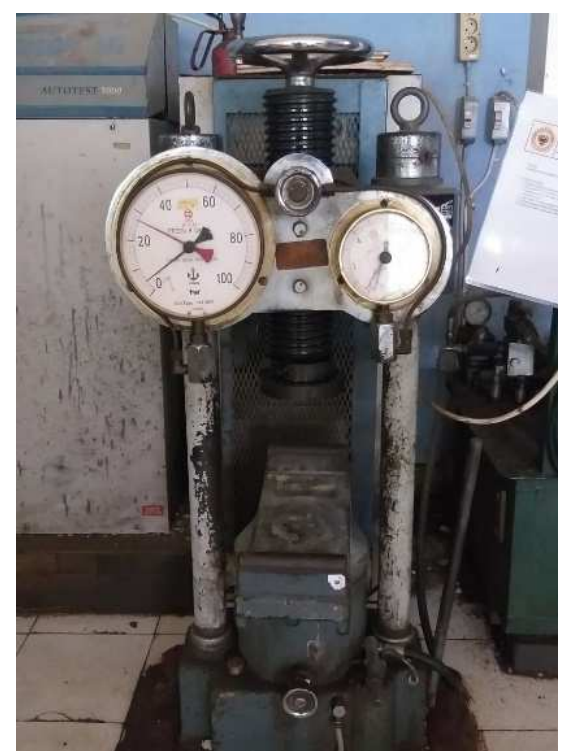

Gambar 3. Compressive strength testing machine

\section{Hasil Kerja}

Evalusi lapangan yang dilakukan adalah pengujian palu beton dengan menggunakan Schmidt Hammer test dan core drilled test pada beberapa titik pada pile- cap seperti yang ditunjukkan pada Gambar 4.

\section{Hasil Pengujian Schmidt Hammer Test}

Beberapa ketentuan dalam melakukan pengujian menggunakan palu beton (alat Schmidt hammer test) yaitu seagai berikut :

1. Pengujian menggunakan Schmidt Hammer Test dalam 1 area minimal terdiri dari 10 titik

2. Jarak antara titik dalam pengujian ini adalah dengan mengambil jarak $>25 \mathrm{~mm}$.
3. Hasil pengujian schmidt hammer test pada prinsipnya adalah mengkonversikan hasil pengujian palu beton (rebound hammer) terhadap benda uji silinder beton yang melihat kondisi keseragaman mutu beton di Lapangan.

Gambar 5 menunjukkan proses pengujian palu beton dengan alat Schmidt hammer test yang dilakukan di Lapangan untuk elemen struktur.

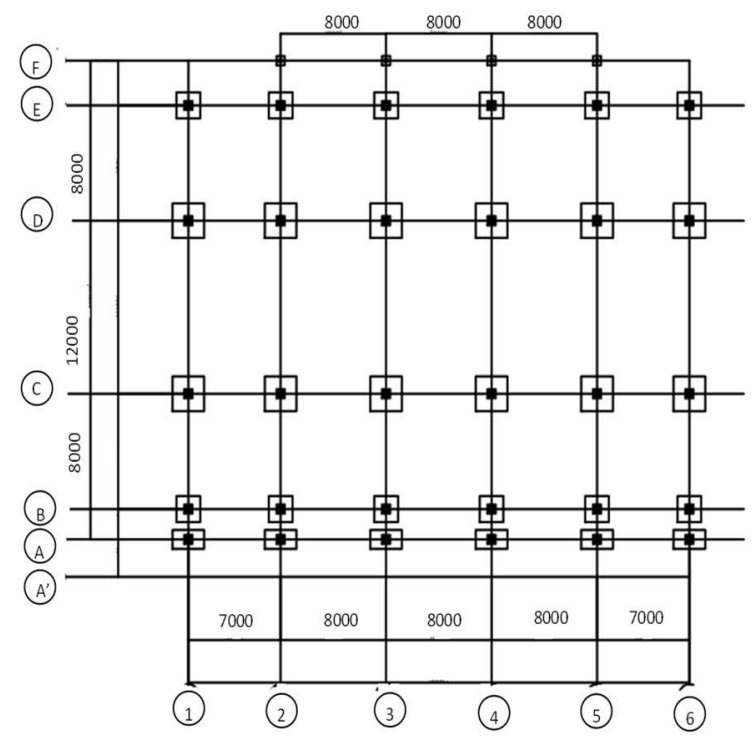

Gambar 4. Denan Pilecap yang akan diujı untuk scnmiat Hammer Test dan Coredrill test

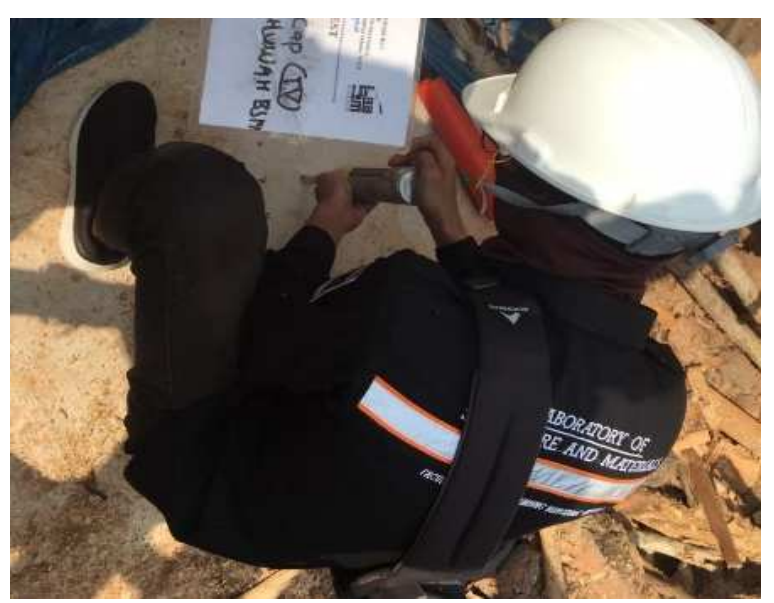

Gambar 5. Proses pengujian dilapangan dengan Schmidt Hammer Test

Tabel 3 menunjukkan hasil pembacaan nilai Rebound Hammer Test (R) dengan alat Schmidt Hammer Test di Lapangan untuk keseluruhan sampel elemen struktur pada Pile cap 1, Pile cap 2 dan Pile cap 3.

Gambar 6 dan Gambar 7 menggambarkan grafik hubungan angka rebound hammer dengan nilai keseragaman beton yang diuraikan sebagai kekuatan tekan beton dengan data yang diperoleh pada Tabel 3 berdasarkan hasil pengujian di Lapangan. 
Tabel 3. Hasil Pembacaan nilai Rebound Hammer pada Schmidt Hammer Test di Lapangan

\begin{tabular}{|c|c|c|c|c|c|c|}
\hline \multirow[t]{3}{*}{ Titik } & \multicolumn{6}{|c|}{ Hasil Pengujian R Sudut $\left(-90^{\circ}\right)-\mathrm{MPa}$} \\
\hline & \multicolumn{2}{|c|}{ Pile Cap I } & \multicolumn{2}{|c|}{ Pile Cap II } & \multicolumn{2}{|c|}{ Pile Cap III } \\
\hline & $R$ & $f^{\prime} c$ & $R$ & $f^{\prime} c$ & $R$ & $f^{\prime} c$ \\
\hline 1 & 26 & 24,40 & 23 & 19,60 & 23 & 19,60 \\
\hline 2 & 22 & 18,06 & 19 & 13,64 & 24 & 21,17 \\
\hline 3 & 23 & 19,60 & 19 & 13,64 & 26 & 24,40 \\
\hline 4 & 22 & 18,06 & 22 & 18,06 & 222 & 18,06 \\
\hline 5 & 25 & 22,77 & 23 & 19,60 & 24 & 21,17 \\
\hline 6 & 22 & 18,06 & 18 & 12,24 & 25 & 22,77 \\
\hline 7 & 28 & 27,74 & 18 & 12,24 & 28 & 27,74 \\
\hline 8 & 22 & 18,06 & 18 & 12,24 & 27 & 26,05 \\
\hline 9 & 28 & 27,74 & 20 & 15,08 & 23 & 19,60 \\
\hline 10 & 24 & 21,17 & 17 & 10,88 & 23 & 19,60 \\
\hline
\end{tabular}

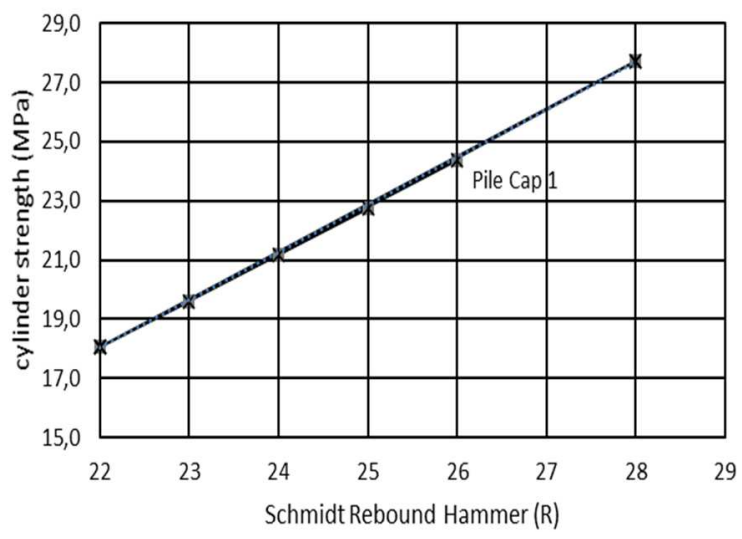

Gambar 6. Hubungan nilai rebound hammer (R) kekuatan silinder beton dengan Schmidt Hammer Test

ACl 214R-02 tentang Evaluation of strength test results of concrete menyebutkan bahwa jika tingkat koefisien variasi beton melebihi angka $6 \%$ maka beton diindikasi memiliki tingkat keseragaman yang kurang baik.
Tabel 4. Hasil Pengujian Schmidt Hammer Test di Lapangan

\begin{tabular}{|c|c|c|c|c|c|}
\hline $\begin{array}{l}\text { Elemen } \\
\text { struktur }\end{array}$ & $\begin{array}{l}\text { Nilai } \\
\text { Maks } \\
\text { (MPa) }\end{array}$ & $\begin{array}{l}\text { Nilai } \\
\text { Minim } \\
\text { (MPa) }\end{array}$ & $\begin{array}{l}\text { Nilai } \\
\text { Rata- } \\
\text { rata } \\
(\mathrm{MPa})\end{array}$ & SD & $\begin{array}{c}\text { Koefisien } \\
\text { variasi } \\
\text { (\%) }\end{array}$ \\
\hline $\begin{array}{c}\text { Pile Cap } \\
\text { । }\end{array}$ & 25,49 & 17,64 & 21,56 & 3,93 & 18,21 \\
\hline $\begin{array}{c}\text { Pile Cap } \\
\text { II }\end{array}$ & 17,96 & 11,48 & 14,72 & 3,24 & 21,99 \\
\hline $\begin{array}{c}\text { Pile Cap } \\
\text { III }\end{array}$ & 25,17 & 18,85 & 22,01 & 3,16 & 14,36 \\
\hline
\end{tabular}

Dari hasil pengujian Schmidt hammer test yang ditunjukkan pada Tabel 4 mengindikasikan bahwa nilai koefisien variasi (KV) dari keseluruhan sampel pile cap yang diuji berkisar antara 14,36\%-21,99\%. Hal ini menunjukkan bahwa pengujian melebihi angka $6 \%$ sehingga beton diindikasikan memiliki tingkat keseragaman yang kurang baik berdasarkan ACI 214R-02.

Lebih lanjut, menurut SNI 6680:2016 menyatakan bahwa pengujian Schmidt hammer test hanya untuk mengevaluasi keseragaman beton pada suatu struktur atau untuk menentukan daerah yang akan dilakukan pengambilan sampel beton inti dan tidak dapat digunakan untuk mengevaluasi kekuatan beton struktur. Untuk mengetahui nilai kuat tekan dari sampel yang diuji dilanjutkan dengan pengujian beton inti (core drill test).

Hasil Evaluasi Pengujian Merusak (Destructive Test: Core Drilled Test)

Menurut SNI 6680:2016 bahwa jika kekuatan beton diragukan, beton inti (core drill) harus diambil dan diuji sesuai dengan ASTM C42/C42M. Jumlah sampel beton inti yang diambil dalam satu area minimal terdiri dari tiga (3) buah sampel beton inti. Hasil pengujian kekuatan beton inti dari coredrilled test merupakan hasil pengujian kuat tekan. Dalam proyek ini pengujian sampel beton inti dilakukan di Laboratorum Material dan Struktur Fakultas Teknik ULM yang menggunakan Compression testing Machine test. Gambar sampel

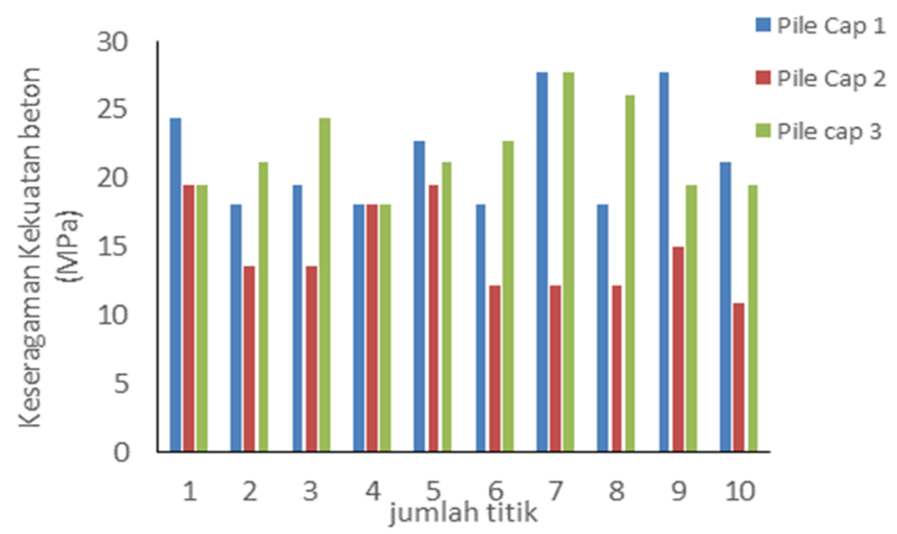

Gambar 7. Hasil Pengujian keseragaman beton dengan alat Schmidt Hammer Test 
beton inti hasil core drilled test ditunjukkan pada Gambar 8

Hasil evaluasi kuat tekan core drilled test untuk pile cap 2 yang terkoreksi ditunjukkan pada Tabel 5 dan Tabel 6. Tabel 5 adalah faktor koreksi penentuan nilai C0, C1 dan C2 dari sampel beton inti dan Tabel 6 menunjukkan hasil pengujian kekuatan beton inti pada umur 28 hari.

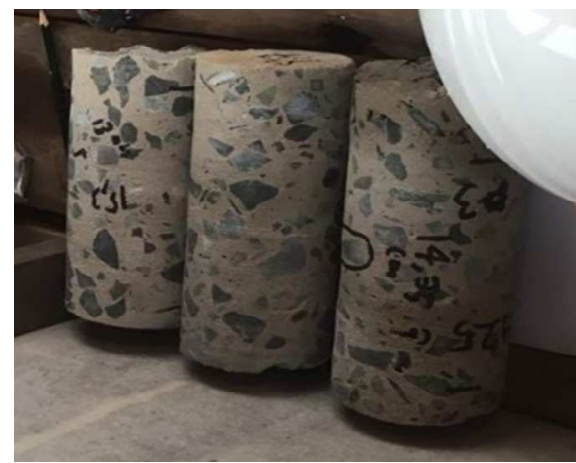

Gambar 8. Sampel beton inti (Coredrilled samples)

Tabel 5. Faktor Koreksi CO, C1 dan C2

\begin{tabular}{clllll}
\hline $\begin{array}{c}\text { Pile cap } \\
2\end{array}$ & L/d & L & Co & C1 & C2 \\
\hline Sampel 1 & 1,50 & 13,7 & 1 & 0,95 & 1,12 \\
\hline Sampel 2 & 1,5 & 11,5 & 1 & 0,96 & 1,12 \\
\hline Sampel 3 & 1,25 & 13,8 & 1 & 0,93 & 1,00 \\
\hline
\end{tabular}

Tabel 6. Hasil Pengujian core drill sample di Lapangan

\begin{tabular}{cccc}
\hline Pile Cap 2 & $d$ & Koreksi & $f_{c}{ }^{\prime}(\mathrm{MPa})$ \\
\cline { 3 - 4 } & & Co.C1.C2 & 28 hari \\
\hline Sampel 1 & 9,17 & 1,08 & 15,86 \\
\hline Sampel 2 & 9,18 & 1,27 & 22,50 \\
\hline Sampel 3 & 9,19 & 1,32 & 16,26 \\
\hline
\end{tabular}

Nilai $f_{c}{ }^{\prime} 28$ hari dari Tabel 6 adalah nilai $f_{c}{ }^{\prime}$ beton inti yang pada Umur 28 hari. Menurut SNI 6880: 2016 pasal 1.5.6.2 untuk persyaratan penerimaan hasil menyatakan bahwa kekuatan beton di daerah yang diwakili oleh hasil uji beton inti memadai bilai kuat tekan rata-rata beton inti minimal $85 \%$ dari $f_{c}{ }^{\prime}$ dan jika tidak ada satupun beton inti yang kurang dari $75 \%$ dari $\mathrm{f}_{\mathrm{c}}{ }^{\prime}$. Target mutu beton yang diperkirakan adalah $\mathrm{f}_{\mathrm{c}}{ }^{\prime}=25$ MPa. Tabel 7 menunjukkan hasil analisis penerimaan untuk kuat tekan sampel beton inti pada Pile Cap 2 .

Dari Tabel 7 menunjukkan hasil pengujian sampel beton inti tidak memenuhi persyaratan untuk target mutu beton sebesar $25 \mathrm{MPa}$. Lebih lanjut, untuk menganalisis kuat tekan beton eksisting dari hasil sampel beton inti yang diambil dapat dilakukan dengan menggunakan beberapa kali trial pemilihan mutu beton yang sesuai yang hasil akhirnya ditunjukkan pada Tabel 8.
Berdasarkan analisis penerimaan hasil kuat tekan beton inti dari Tabel 8 dapat disimpulkan bahwa kuat tekan beton inti yang diperoleh dari sampel beton inti (core drilled samples) adalah sebesar $21 \mathrm{MPa}$.

Tabel 7. Penerimaan hasil kuat tekan beton inti dilapangan

\begin{tabular}{llll}
\hline \multicolumn{1}{c}{ Persyaratan } & $\begin{array}{c}\text { Standar } \\
\text { minimum } \\
\text { (MPa) }\end{array}$ & $\begin{array}{c}\text { Mutu } \\
\text { beton } \\
\text { inti } \\
(\mathrm{MPa})\end{array}$ & Keterangan \\
\hline $\begin{array}{l}\text { Rata-rata tiga } \\
\text { sampel beton } \\
\text { inti }>85 \% \mathrm{f}_{\mathrm{c}}{ }^{\prime}\end{array}$ & & 18,20 & Tdk memenuhi \\
\hline $\begin{array}{l}\text { Masing-masing } \\
\text { beton inti }>75 \%\end{array}$ & & & \\
$\mathrm{f}_{\mathrm{c}}{ }^{\prime}$ & & & \\
\hline Sampel 1 & 18,75 & 15,86 & Tdk memenuhi \\
\hline Sampel 2 & 18,75 & 22,50 & memenuhi \\
\hline Sampel 3 & 18,75 & 16,26 & Tdk memenuhi \\
\hline
\end{tabular}

Tabel 8. Analisis kuat tekan beton inti eksisting dilapangan

\begin{tabular}{lccc}
\hline \multicolumn{1}{c}{ Persyaratan } & $\begin{array}{c}\text { Standar } \\
\text { minimum } \\
\text { (MPa) }\end{array}$ & $\begin{array}{c}\text { Mutu } \\
\text { beton } \\
\text { inti } \\
(\mathrm{MPa})\end{array}$ & Keterangan \\
\hline $\begin{array}{l}\text { Rata-rata tiga } \\
\text { sampel beton } \\
\text { inti }>85 \% \mathrm{f}_{\mathrm{c}}{ }^{\prime}\end{array}$ & 17,85 & 18,20 & memenuhi \\
\hline $\begin{array}{l}\text { Masing-masing } \\
\text { beton inti }>75 \%\end{array}$ & & & \\
$\mathrm{f}_{\mathrm{c}}{ }^{\prime}$ & & & \\
\hline Sampel 1 & 15,75 & 15,86 & memenuhi \\
\hline Sampel 2 & 15,75 & 22,50 & memenuhi \\
\hline Sampel 3 & 15,75 & 16,26 & memenuhi \\
\hline
\end{tabular}

\section{Kesimpulan}

Dari hasil analisis dan pembahasan dapat disimpulkan bahwa:

1. Hasil evaluasi keseragaman beton dengan menggunakan uji palu beton dengan Schmidt hammer test di Lapangan yang diukur dengan koefisien variasi berkisar antara 14,36\%-21,99\%.

2. Berdasarkan $\mathrm{ACl} 214 \mathrm{R}-02$, keseluruhan pile cap yang diuji memiliki tingkat keseragaman melebihi $6 \%$ yang mengindikasikan bahwa tingkat keseragaman beton kurang baik, sehingga diperlukan assessment lanjutan dengan pengujian merusak (nondestructive test)

3. Hasil pengujian merusak dengan core drill test untuk sampel beton inti tidak memenuhi persyaratan penerimaan sampel untuk target mutu $25 \mathrm{MPa}$ berdasarkan SNI 6680:2016 yang mensyaratkan bahwa kekuatan beton di daerah yang diwakili oleh hasil uji beton inti memadai dengan kuat tekan ratarata beton inti minimal $85 \%$ dari $\mathrm{f}_{\mathrm{c}}{ }^{\prime}$ dan jika tidak ada satupun beton inti yang kurang dari $75 \%$ dari $f_{c}{ }^{\prime}$

4. Hasil kuat tekan beton $f_{c}{ }^{\prime}$ dari sampel beton inti untuk pile cap 2 adalah sebesar $21 \mathrm{MPa}$ 


\section{Ucapan Terimakasih}

Penulis mengucapkan terimakasih kepada Tim Laboratorium Struktur dan Material Program Studi Teknik Sipil, Fakultas Teknik Universitas Lambung Mangkurat yang membantu untuk memfasilitasi dalam penyusunan hasil penelitian ini.

\section{Referensi}

ACl 214-R-02. 2002. Evaluation of Strength Test Results of Concrete.

Alexandre, B.J., Gloria, G.M and Augusto, G. (2013). Compressive Strength Evaluation of Structural Lightweight Concrete by Non-destructive ultrasonic pulse velocity method. Ultrasonics

ASTM C42/C428. Standard Test Method for Obtaining and Testing Drilled Cores and Sawed Beams of Concrete

ASTM C 805-02. 2002. Standard Test Method for Rebound Number of Hardened Concrete

Aydin, F. \& Saribiyik, M (2010). Correlation between Schmidt hammer and destructive compressions testing for concrete in existing building. Scientific Research and Essay, vol.5 (13), pp1644-1648

Badan Standar Nasional. 2010. RSNI 4803-20XX. Metode Uji Angka Pantul Beton Keras (ASTM C805-02)
Badan Standar Nasional. 2016. SNI 6680:2016. Spesifikasi beton struktural.

Badan Standar Nasional. 2002. SNI 02-2492-2002. Metode Pengambilan dan Pengujian beton inti.

Breysse, D. (2012). Non-destructive evaluation of concrete strength: a historical review and a new perspective by combining NDT methods. Construction and Building Materials, 33, 139-163.

Christiawan I, Triwiyono A dan Christady H. 2008. Evaluasi Kinerja dan Perkuatan Struktur Gedung guna Alih Fungsi Bangunan. Forum Teknik Sipil No.XVIII

Karundeng. S.S. 2015. Penerapan Metode Schmidt Hammer Test dan Core Drilled Test untuk Evaluasi Kuat Tekan Beton pada Ruang IGD RSGM Unsrat guna Alih Fungsi Bangunan.

Mawardi. L. 2013. Pengujian Struktur Beton dengan Metode Hammer Test dan Metode Uji Pembebanan (Load Test). Universitas Sumatera Utara. Medan

Malek, J. \& Kaouther, M (2014). Destructive and Nondestructive Testing of Concrete Structures. Jordan Journal of Civil Engineering, vol.8 No 4.

Patil, S.G. \& Suresh (2017). Correlation between Actual Compressive strength of Concrete and Strength Estimated from Core. IOSR Journal of Mechanical and Civil Engineering (IOSR-JMCE), vol.14, issue 2. Ver.III (Mar-April 2017), pp.27-44. 